\title{
IPBES, an inclusive institution? Challenging the integration of stakeholders in a science-policy interface
}

\author{
Mohamed Oubenal $^{1}$, Marie Hrabanski ${ }^{2}$ and Denis Pesche ${ }^{3}$
}

\begin{abstract}
The International Platform for Biodiversity and Ecosystem Services (IPBES) was launched in 2012. Its objective is to strengthen the science-policy interface for the conservation and sustainable use of biodiversity, long-term human well-being, and sustainable development. Nonstate Actors (NSAs) participated in the inception of the platform and are also assumed to play a key role in its coming assessments and reports. In order to encourage NSAs to participate and self-organize, an institutional process has been led by the Secretariat in collaboration with two main organizations: Diversitas-International Council for Science (ICSU) and the International Union for Conservation of Nature (IUCN). We look at the construction of this stakeholder participation process and its effectiveness. To what degree is the stakeholder engagement effective and what are the different forms of involvement? What methods are used by the IPBES's Secretariat and its mandated organizations to encourage stakeholder participation in the Platform? A social network analysis survey revealed four categories of actors in the group of stakeholders: organizers, connected, closely-knit, and peripheral. The ethnographic approach analyzed the way in which the IPBES secretariat organized the stakeholders' days, managed them, and controlled them. Thanks to these two methods, we analyzed the relational structure of the group of stakeholders and their contours of involvement and showed that these two dimensions can combine in a different way. The idea of a group of stakeholders, promoted by IPBES, is accompanied by a leadership/participation model that tends to enroll the stakeholders involved but may conversely marginalize some dissenting voices.
\end{abstract}

Key Words: biodiversity; global governance; IPBES; science-policy interface; social network analysis; stakeholders

\section{INTRODUCTION}

The objective of the International Platform for Biodiversity and Ecosystem Services (IPBES) is to strengthen the science-policy interface for the conservation and sustainable use of biodiversity, long-term human well-being, and sustainable development. IPBES was launched in 2012 after a long process that started in 2008. Nonstate Actors (NSAs) participated in the inception of the platform and are also assumed to play a key role in the coming assessments and reports of IPBES. To encourage NSAs to participate and self-organize, an institutional process has been led by the IPBES secretariat in collaboration with two main organizations: Diversitas-International Council for Science (ICSU) and the International Union for Conservation of Nature (IUCN). The "stakeholder days" during conference plenaries and other informal meetings enabled the creation of a group of NSAs that meet regularly. According to the IPBES secretariat, the creation of a group of IPBES stakeholders is an institutional innovation yet to be seen in similar organizations, notably in the Intergovernmental Panel on Climate Change (IPCC). It is the view of the IPBES secretariat that this innovation would make it possible to take into account the plurality of knowledge and actors and institutionalize that plurality within a group of IPBES stakeholders.

There are trends in global governance calling for "stakeholder democracy" as an important component of transnational democracy (Bäckstrand 2006). Participation is studied with growing attention to improve legitimacy and effectiveness in environmental governance (Hogl et al. 2012). The inclusion of NSAs in global governance is often considered as a first step in this democratic perspective. Some studies seek to understand the effectiveness of NSA participation in global governance focusing on one category like NGOs (Betsill and Corell 2008), indigenous people (Schroeder 2010, Wallbott 2014), or the private sector
(Clapp 2005). Others trace the development of participatory approaches in environmental management and suggest features of best practice in participation (Reed 2008). But few researchers analyze the modalities of stakeholder involvement, in their diversity, and the characteristics of their interactions in the participation process within a specific international organization. Despite evidence on NSAs growing participation in global governance (Arts 2000, Higgott et al. 2000, Nasiritousi et al. 2016), the links between the characteristics of the engagement process and the participation effectiveness remain underexplored.

We look at the construction and effectiveness of this stakeholder participation process in IPBES. This institution reviews scientific literature and takes into account other backgrounds such as indigenous and local knowledge (ILK) to produce up-to-date assessments on issues related to biodiversity (Duperray et al. 2016). The production of this new knowledge needs involvement and collaboration between IPBES's participants, including stakeholders. Although Morin et al. (2016) studied interdependencies between experts of the multidisciplinary expert panel (MEP) and bureau members of IPBES, we suggest focusing on IPBES's stakeholders. The inclusiveness of IPBES can thus be analyzed by studying the exchange of knowledge and expertise through advice-seeking and advice-giving.

We analyze the exchange of knowledge through advice-seeking and advice-giving between IPBES stakeholders and the types of involvement that result from the integrative model implemented by the IPBES secretariat and its mandated organizations. We focus only on one segment of IPBES, which is the stakeholder group. It is thus not possible to generalize our results to the whole institution. Further research may deal with other segments of IPBES such as MEP and bureau members (Morin et al. 2016), task forces, or country delegations. We show that the leadership 
dynamics managed by the IPBES secretariat convey a precise participation model, which tends either to enrol the stakeholders involved or leads them to self-exclude themselves from the group. The group of stakeholders comprises individuals who maintain heterogeneous relations within the group and who also have diverse contours of involvement. The notion of involvement contour was introduced by Goffman (2013) to show that actors are involved differently in the same scene. For instance, two persons saying the same word may express it with an opposite tone. Building on this notion, Cefaï et al. (2012) suggested using contours of involvement to describe the profiles of actors' participation in deliberative processes. This depends on a combination of the nature and intensity of participation processes.

\section{WHAT DOES THE TERM STAKEHOLDER STAND FOR IN IPBES? ANALYSIS AND CHALLENGES}

We analyze how the stakeholder concept is used by IPBES, showing that this concept brings together organizations that are perfectly heterogeneous through their purpose and their interests, and that the roles assigned to the stakeholders are also diversified. In fact, these aspects raise questions surrounding the dynamics of stakeholders' participation.

Since the first IPBES meeting in 2008, the issue of the role played by nongovernmental stakeholders was the subject of discussions. For IPBES, stakeholders are scientific organizations, NGOs, but also private sector and intergovernmental or national public bodies viewed as "IPBES users" (IPBES 2013). At the first plenary session in Bonn in January 2013, ICSU and IUCN were given a mandate to coordinate the establishment of a stakeholder involvement strategy with a view to supporting the IPBES work program. Moreover, nongovernmental organizations such as IUCN and ICSU often act as bridging organizations within the natural resource governance arena (Kowalski and Jenkins 2015). Considerable technical, financial, and personnel resources enable these two NGOs to effectively link actors across institutional and spatial boundaries (Mitchell 2010).

IPBES conception of stakeholder involvement is a fairly utilitarian vision of stakeholders who are seen as both (1) making their contribution to the work program, in the form of information, expertise, etc., and (2) as users of the outputs of the work program, as the target of IPBES or its "clients" and "end users" (IPBES, 2013). In the revised strategy document, the question of selecting stakeholders was clearly raised to limit their number and guarantee their relevance for the IPBES process (IPBES 2014).

Last, stakeholders are involved in the IPBES process in ways that are kept in check by facilitators (ICSU and IUCN). A selection process is carried out first, by way of solicitation and accreditation logics. To be accredited, stakeholders should contact organizers, and obviously it is more difficult for small organizations to have the financials and materials resources to send a representative to international meetings. Second, selection process is carried out through the involvement dynamics of stakeholders who decide to take part in the process, by attending several meetings or no longer taking part in it. We combined two complementary methods: ethnographic observation and a social network analysis to study the degree of involvement of stakeholders.

\section{OBSERVING STAKEHOLDERS DURING MEETINGS AND ANALYSING THE ADVICE NETWORK}

The ethnographic observation of stakeholder days helped to characterize the set of interactions existing between the stakeholders attending the IPBES stakeholder meetings. A description of assembly scenes brought out some interaction mechanisms or collective dynamics that are usually not much taken into account in the literature. Building on Cefaï et al. (2012) and Goffman (2013), our observations relied first and foremost on analyzing the time sequencing of the stakeholder days (When and how did the stakeholder days proceed?), then on the voicing of opinions ("Who" took part in the stakeholder days and "how" did they participate?); this made it possible to see which stakeholders gained the upper hand and those who remained on the sidelines. To distinguish between collaborative and dissenting voices we confronted our three observations. When individuals generally adhere to the ideas and propositions made by workshop facilitators we range them as cooperative actors but when they challenge facilitators' views we consider them as dissenting actors. For instance, indigenous representatives, whom we range as dissenting actors, wanted to have a partner status but facilitators considered this a political dimension that should be discussed elsewhere.

We completed this ethnographic observation with a social network analysis (Wasserman and Faust 1994, Lazega 2007, Scott 2014) of advice interactions between stakeholders. This enabled us to study the interdependencies existing between stakeholders and determine the different types of stakeholder involvement. IPBES is a knowledge-intensive organization in which actors need to exchange and transfer expertise to produce accurate assessments. Moreover, IPBES's stakeholder group can be considered as a collegial body (Lazega 2001) that mobilizes the expertise and knowledge of its members to deal with complex environmental issues (Isaac et al. 2007). Thus, advice is one of the main resources that enables IPBES stakeholders to produce reports, expertise, or position papers. Those who are more involved in this platform are more active in sharing information. We thus questioned 48 participants during the stakeholder days of the plenary session, asking them the following sociometric question: When you want to take a position (or produce a position paper) on a subject related to IPBES who are the people from the list of 48 actors whom you ask for advice? We then constructed some groups according to the relational proximity of the stakeholders in the directed advice network (Lorrain and White 1971, Lazega and Pattison 1999, Lazega et al. 2012). Based on the matrix of the stakeholder advice network we calculated the relational proximity between two individuals within the network using Ward's method that provides hierarchical clustering (cf. Appendix 1 for the methodological aspects and the dendrogram). Hierarchical clustering led to the identification of four subgroups of stakeholders, within which the individuals displayed relational proximities.

Our ethnographic observations of the voicing of viewpoints from 7 to 14 December 2013 enabled us to define some specific forms of stakeholder involvement. Based on two analytical variables, the frequency with which viewpoints were voiced (who speaks) and the style in which they were delivered (collaborative voicing of views or more critical and challenging), we brought out different contours of involvement (Goffman 2013). We deduced 
from them heterogeneity in the dynamics of IPBES stakeholder participation, which combined the relational structure of participants and their contours of involvement.

\section{MANAGEMENT AND CONTROL OF STAKEHOLDER INTERACTIONS DURING IPBES MEETINGS}

We analyzed the characteristics of the meetings observed. These ethnographic elements highlight the way in which the IPBES secretariat organized these meetings, managed them and controlled them. This organization revealed both the supervisory process and the will to keep control over the group of stakeholders, while also revealing the framework of interactions between the stakeholders. Indeed, these interactions were fashioned, or even constrained, by the very organization of the stakeholder days.

Since the first plenary session in Bonn in January 2013, each plenary session has been preceded by stakeholder days. These two days of work are organized on the weekend preceding the official opening of the meeting and are intended to produce common positions between the different members of the group of stakeholders. The plenary sessions are organized during a week with stakeholders meeting each morning and participating as observers to the plenary sessions. Our participant observation of the IPBES stakeholder days and plenary sessions took place from 7 to 14 December 2013, at the second IPBES conference in Antalya, Turkey, in a luxurious seaside hotel. The facility where the meeting took place could be a strong constraint to participate because of the high rates of these kind of hotels, especially for the poorest stakeholders. The hotel was home to all the participants (stakeholders and delegations, IPBES bureau and multidisciplinary expert panel) for the whole period.

\section{A formal framework}

The stakeholder days were held in a large conference room different from the plenary session room. The fact that all of the IPBES participants were brought together in the same place for several days helped the stakeholders to become acquainted with each other and with the nonstakeholders including members of the multidisciplinary expert panel (MEP), the bureau, and the governmental delegations, who arrived before the plenary session and also took part in the stakeholder days. At the Antalya session (IPBES-2), the stakeholder days benefited from considerable visibility (information panels, catering signage, etc.). Likewise, the layout of the room in which the event was held, its equipment in terms of lighting and image technologies, and its ecological arrangement (presence of objects, room size, organization of seating, visibility of symbols, etc.) were all signs that marked the desire to make it an important moment and thereby strengthen the interest of the participants in the initiative. This arrangement also made it possible to control the nature of the stakeholder debates because the event actually took place in a conference room, which thus presupposed the adoption of a tone that was polite, discursive, and even technical. This formality and the seriousness of the moment were strengthened by the use of PowerPoint and advanced lighting technologies. The layout of the conference room also gave central place to the facilitators of the stakeholder days coming from ICSU-Diversitas and IUCN: seated on a platform, above the participants lined up behind small tables. The representative from ICSU-Diversitas opened the meeting, followed by the representative of the IPBES provisional secretariat, then a representative of FAO and UNESCO. These official introductions tended to add gravitas to the moment, and each speaker hammered out the same message: stakeholders "must" participate in the process, so that they can be a force for proposals. The tone was solemn and highlighted the ambitions of the stakeholders and the importance assigned to the participants.

After this first formal moment came the time to "break the ice." This sequence was led by a young woman who asked each of the participants to answer a question using one of the four colored cards proposed. The moment was entertaining and, in particular, enabled the participants to count each other and get to know or recognize each other. Although almost 150 participants were expected only around 60 were present. By way of the colored cards, the session leader brought out the fact that almost half the participants were European, there were also 10 participants from North America and Asia, and a few participants from South America, Africa, and the Pacific. Men were over-represented (around $65 \%$ of the assembly). Despite the IPBES's will to reach some geographical balance and gender balance goals, the traditional dominant categories and regions, men and western countries, were mostly involved in the stakeholders meetings. A second question concerned the number of people attending the stakeholder days for the first time and the final question concerned the type of stakeholders attending: government, NGO, research, etc.

\section{Controlled proceedings}

The whole meeting lasted three half days, divided into three periods with (1) a first period of IPBES general presentation, highlighting the still inclusive nature of the process ("new" people were welcomed and IPBES's function explained to them), (2) a second period devoted to the stakeholder involvement strategy, which was the subject of a specific debate during the plenary session, and (3) a third period aimed at preparing a dialogue with a few members of the MEP and the bureau, and a joint declaration of the stakeholders.

After the introduction mentioned above, the first half-day was devoted to the general presentation of IPBES and the contents of the agenda for this second plenary session. Several speeches by representatives of the IPBES provisional secretariat (UNEP) provided a reminder of IPBES's functioning and the expected role of the stakeholders: a reminder of the background of IPBES and its links with the other conventions and science-policy interfaces (IPCC and Millennium ecosystem assessment, etc.) helped to legitimize IPBES politically and scientifically. Through the format of its presentation, this preliminary framing clearly illustrated the highly "productive" expectations of stakeholder participation, which was mainly considered as a contribution to the platform's work program.

A second session was constructed around the following objective: enrich the strategy for stakeholder involvement in IPBES. This involvement strategy document existed in provisional form and was to be discussed at the next plenary session. The session was introduced by several people taking the floor, directed from the platform, with notably a female representative of indigenous peoples, a female representative from the private sector, from an association linked to the world of research. It was then proposed to work in small groups on several topics to improve the participants' acquaintance with each other and facilitate verbal expression. This working session in small groups was guided by 
a document given beforehand to the participants: "Considerations for the further development of a Stakeholder Engagement Plan (7-8 December 2013)." This 9-page document included a table with a set of already formulated ideas on how stakeholders could contribute. Here again, the care taken to facilitate the meeting clearly showed very close channelling of the answers expected from the participants. During the general debate a few speakers questioned the process as such: How was the panel of 1500 people compiled to call upon the stakeholders? The organizers explained that, in 2010, they assembled nongovernmental stakeholder lists drawn up by IUCN and UNEP, in connection with the UN "major groups." Another question raised possible disagreements between stakeholders and a participant asked about the existence of a database of stakeholders, and about the difference between observers, member countries, and stakeholders. Without giving rise to any stormy debates, these few questions highlighted the, as yet, uncertain nature of the process and the mistrust mainly expressed by a small minority of people. This challenges the stakeholder's participation philosophy based on empowerment, equity, trust, and learning (Reed 2008).

The third session, the final half-day of the stakeholder days, was devoted to preparing the dialogue with some official representatives of IPBES, from the MEP and the bureau. A few members of the MEP and the bureau interacted with the floor around questions of governance and the role of stakeholders in the IPBES process. During the exchanges, the representatives of the indigenous groups marked their difference by calling for specific recognition as a partner group, like that obtained in The Convention on Biological Diversity (CBD) and on UN bodies in general (Mauro and Hardison 2000, Coombe 2001, Wallbott 2014).

Most of the stakeholders agreed in acknowledging the importance of prior consultation and the fact that various consultations need to enable stakeholder viewpoints to be heard by governmental delegations. The issue of the diversity of viewpoints was touched upon again, countering the stated quest of the organizers for a common stakeholder position. We find here two of the key features identified by Reed (2008) which consist of associating relevant stakeholders earlier in the process and choosing a deliberative approach that explores the diversity of views instead of seeking consensus.

\section{RESULTS: RELATIONAL STRUCTURES AND CONTOURS OF INVOLVEMENT}

Some of the participants in the stakeholder days knew each other. Some were newcomers to this arena. The first stage in our work was to analyze the relational structures of the group. Then, based on ethnographic observations, we analyzed the frequency with which viewpoints were voiced and thereby qualified the understanding of participation dynamics.

\section{Heterogeneous relational structures within the IPBES group of stakeholders}

In order to check for the establishment of a group of stakeholders who collectively take part in the work of the IPBES platform, we carried out a social network analysis of advice interactions between the different stakeholders. This enabled us to describe the structure of interdependencies between the different stakeholders and determine which of them were most integrated within this group and those who seemed isolated. By grouping the stakeholders according to their relational proximity (see Appendix 1 for the approach adopted) we were able to determine four subgroups: the 3 organizers, the connected group that includes 17 actors, the 5 closely-knit, and 23 forming the peripheral group (Fig. 1). For each of the subgroups of our directed network, we analyzed the density of relationships inside the subgroup and the density of connections to other subgroups. We measured the density by dividing the existing relationships on the possible interdependencies. For example, the density inside the closely-knit group, which includes 5 actors, is calculated by dividing the 16 relationships between the members by the maximum number of possible interdependencies which is 20 $(5 * 4)$.

Fig. 1. Advice exchange network between four subgroups defined according to their relational proximity.

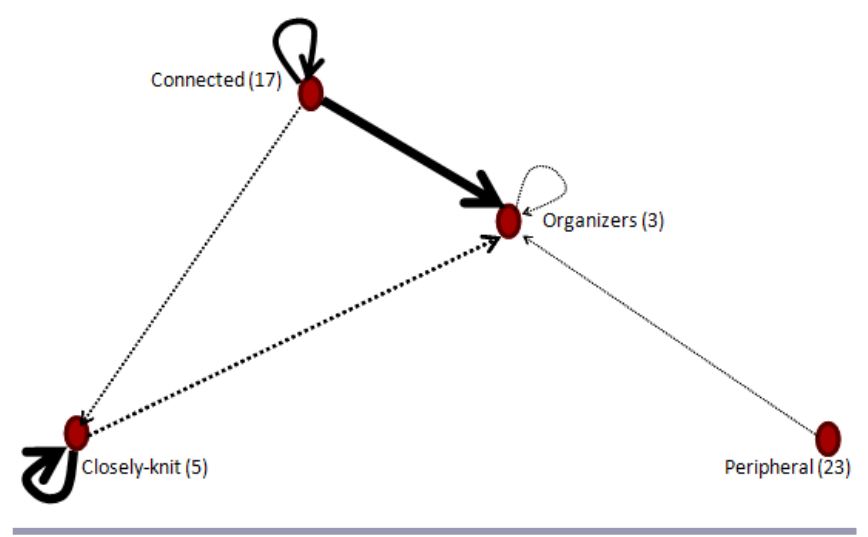

Percentages in the diagonal correspond to the within-group density inside each subgroup. For instance, $33.33 \%$ is the density inside the organizers' subgroup (Table 1). It corresponds to the existence of two among the six possible interactions. The other percentages in the table correspond to the existing ties between each two different subgroups divided by the maximum number of possible relationships between them. For instance, $88.24 \%$, which is the highest score in the network, means that nearly all the 17 stakeholders in the connected subgroup asked the 3 organizers for advice.

Table 1. Density of intra and intersubgroups.

\begin{tabular}{lcccc}
\hline \hline & Organizers & Connected & Closely-knit & Peripheral \\
\hline Organizers & $33.33 \%$ & $4.09 \%$ & $7.83 \%$ & $7.51 \%$ \\
Connected & $88.24 \%$ & $43.38 \%$ & $20.00 \%$ & $7.67 \%$ \\
Closely-knit & $26.67 \%$ & $9.41 \%$ & $80.00 \%$ & $7.83 \%$ \\
Peripheral & $16.67 \%$ & $9.80 \%$ & $0.00 \%$ & $2.90 \%$ \\
\hline
\end{tabular}

The first two subgroups (organizers and connected) displayed a relational structure showing their strong involvement in the process. The organizers were the most central subgroup. Other members of the stakeholder group asked for advice to the three organizers in an intensive way. Each of the three organizers displayed a similar relational structure: they were all three called upon by the other members of the network. The group of 
Table 2. Composition of the subgroups according to the type of organization and geographical zone.

\begin{tabular}{|c|c|c|c|c|}
\hline \multirow{2}{*}{ Organizers } & \multicolumn{2}{|l|}{ Type of organization } & \multicolumn{2}{|c|}{ Geographical zone } \\
\hline & $\begin{array}{l}\text { Scientific organization } \\
\text { Environmental NGO }\end{array}$ & $\begin{array}{l}2 \\
1\end{array}$ & Europe & 3 \\
\hline Connected & $\begin{array}{l}\text { Biodiversity plateform } \\
\text { Environmental NGO } \\
\text { Scientific organization }\end{array}$ & $\begin{array}{l}5 \\
3 \\
9\end{array}$ & Europe & 17 \\
\hline Closely-knit & Indigenous and local communities & 4 & $\begin{array}{l}\text { North America } \\
\text { Africa } \\
\text { Latin America } \\
\text { Asia }\end{array}$ & $\begin{array}{l}1 \\
1 \\
1 \\
1\end{array}$ \\
\hline & Scientific organization & 1 & Europe & 1 \\
\hline Peripheral & $\begin{array}{l}\text { Indigenous and local communities } \\
\text { Biodiversity platform } \\
\text { Business group } \\
\text { Environmental NGO } \\
\text { Scientific organization }\end{array}$ & $\begin{array}{l}2 \\
2 \\
3 \\
4 \\
12\end{array}$ & $\begin{array}{l}\text { Latin America } \\
\text { Australia } \\
\text { Asia } \\
\text { North America } \\
\text { Europe }\end{array}$ & $\begin{array}{l}1 \\
1 \\
2 \\
8 \\
11\end{array}$ \\
\hline
\end{tabular}

organizers also had a relative high within-group density $(33.33 \%)$, which means the existence of two among the six possible interactions. The density among organizers was lower than the connected and closely-knit subgroups because a score higher than $50 \%$ would necessary mean the existence of reciprocity between organizers, which is quite difficult regarding the nature of the advice resource exchanged. Since IPBES was launched, the three members making up this subgroup have played a central role in constructing the group of stakeholders. This subgroup is therefore called upon by all the groups but never asks for advice from the others (the scores in the first row of Table 1). This shows recognition of the legitimacy of this subgroup by all the others and the fact that this subgroup does not feel the need to ask others for advice.

Each of the 17 members of the connected group also displayed a similar relational structure. The group calling most upon the organizers was the connected group (88.24\%). Indeed, nearly all the 17 stakeholders in this subgroup asked the 3 organizers for advice. This was the highest score in the entire network. Withingroup density for the connected group (43.38\%) was even higher than among the members of the organizer group (33.33\%), which means a strong homophilic tendency if we take into account that all members of the connected group are in the European region (see Table 2). The members of the connected group were the only ones to ask the closely-knit group for advice. However, the connected group did not risk rivalling the organizers because they were not called upon by any other group.

The following two subgroups, the closely-knit and peripheral, were more isolated in the network. The closely-knit group displayed a very different relational structure effect in that the five stakeholders making up this subgroup seemed to be relatively isolated from the stakeholders most involved in the process (organizers and connected). These five members had the highest within-group density ( $80 \%)$, meaning that the advice exchange and coordination logics were very considerable in this subgroup. This subgroup is homophilic because almost all its members were representatives of indigenous and local communities (ILCs). In contrast, its requests for advice from the other groups were limited to a strict minimum. These stakeholders very rarely called upon the organizers $(26.67 \%)$. Their isolation was even further verified when observing that they were only occasionally called upon by the connected group $(20 \%)$.

Last, the peripheral group ( 23 members) was the most isolated in the network. It was not called upon by any of the other subgroups and did not ask for advice from any group other than the organizers (see the fourth row in Table 1). Participation of the members of the peripheral group was not only the minimum within the group of stakeholders but they did not even constitute a closely-knit group because their within-group density was extremely low (2.9\%); they did not call upon each other and they had no exchanges.

The composition of the peripheral group shows the difficult integration of certain categories of stakeholders and certain geographical zones. Indeed, all the representatives of business organizations were in the peripheral group and even though the organizers attempted to involve them in the group, their participation remained very low key. The two representatives of the human sciences section of the scientific NGOs were also in the peripheral group. However, it can be said that the latter were able to benefit from other channels to express themselves within IPBES, such as via ICSU, or directly via the MEP. This aspect is an important point insofar as some members of the stakeholders "only" have the stakeholder days to express their viewpoint, whereas others benefit from one or more other channels (MEP, delegations, etc.) to make their position known within IPBES. As regards the geographical zones, we found that the two representatives of Asian institutions were on the edge of the group of stakeholders. Some other representatives from the USA, Australia, and the UK were also in the peripheral group. It should be noted that some representatives from African or Latin American institutions were not present at all in the group of stakeholders (those in Table 2 are representatives of ILCs and do not represent scientific organizations or environmental NGOs). On the other hand, the continental European zone was the most integrated within the group of stakeholders.

\section{Discursive style and dynamics of voicing viewpoints: avoiding disagreements and producing common sense}

Unlike the IPBES plenary sessions, there is no translation during the stakeholder days and the working language is English, 
conveying a shared communication norm. Our ethnographic work also enabled us to analyze discussion styles, which were more or less formal or relaxed, from the most antagonistic where conflict seemed to be promoted, to the most conciliatory where all compromises were possible to avoid conflict, to the most rational where the quest for the best argument prevailed. The observations of the stakeholder days highlighted the will to avoid disagreements and achieve a consensus among the participants instead of having a deliberative approach (Reed 2008). The terms used were borrowed from Anglo-Saxon management semantics: capacity building, benchmarking, consensus building. These terms have a low emotive value, but a strong instrumental and functional value by avoiding any ideological or political reference. The rhetoric used by the organizers was not dissuasive, even when the indigenous representatives wished to be considered as partners. The rhetoric used did not seek to impose a single vision either, but sought above all to find a common meaning on which all could agree. The meetings of the stakeholder days served somewhat as a secondary socialization event (Berger and Luckmann 1991) making it possible to take on board new standards and rules, a way of saying and doing that reasoned with the expectations of the group. An international meeting like that of the IPBES stakeholder days demands demonstrations of respect and courtesy at all times, precisely because nobody knows where the acceptable limits of verbal argumentation lie for their partners. Through their participation, the stakeholders who had not yet been socialized to these standards learned the rules of conduct (Van Vree 2001). Some precise, constant, and smooth behaviors are instilled, which constrained expressions of affect and emotion.

\section{Relational structures and contours of involvement}

The network analysis revealed four categories of actors in the group of stakeholders: organizers, connected, closely-knit, and peripheral. The ethnographic analysis was used to further finetune these four categories by analyzing the contours of involvement within each of them. Table 3 shows the different categories of stakeholders and the diversity of contours of involvement.

Table 3. Contours of involvement of stakeholders categories.

\begin{tabular}{|c|c|c|c|c|}
\hline & $\begin{array}{c}\text { Frequent } \\
\text { voicing of } \\
\text { views }\end{array}$ & $\begin{array}{l}\text { Limited } \\
\text { voicing of } \\
\text { views }\end{array}$ & $\begin{array}{c}\text { Cooperative } \\
\text { stance }\end{array}$ & $\begin{array}{c}\text { Dissenting } \\
\text { stance }\end{array}$ \\
\hline Organizers & $\mathrm{x}$ & & $\mathrm{x}$ & \\
\hline closely-knit & & $\mathrm{x}$ & & $\mathrm{x}$ \\
\hline Connected 1 & $\mathrm{x}$ & & $\mathrm{x}$ & \\
\hline Connected 2 & $\mathrm{x}$ & & & $\mathrm{x}$ \\
\hline Peripheral 1 & & $\mathrm{x}$ & $\mathrm{x}$ & \\
\hline Peripheral 2 & & $\mathrm{x}$ & & $\mathrm{x}$ \\
\hline
\end{tabular}

The organizer and closely-knit categories each displayed uniform contours. The organizers were the most active members of the stakeholders and displayed a uniform contour of involvement. It was they who most voiced views. Beyond a simple leadership role, they highlighted the different challenges; they put forward the different options offered to the stakeholders and thereby guided the debates. Indeed, by only taking an interest in the process of constructing the stakeholder group and in its claims, the organizers put aside other types of issues they considered not to be the concern of the group. While taking care not to gloss over the different types of stakeholders, their aim was to find points of consensus and create a common interest around points of procedure.

The closely-knit group was composed of the indigenous groups and also displayed the same contour of involvement. These actors were particularly courted within the group of stakeholders because the inclusion of nonscientific knowledge in IPBES is one of the major challenges of the platform (Buizer et al. 2011, Turnhout et al. 2012, Opgenoorth and Faith 2013, Thaman et al. 2013). These representatives rarely voiced their views over the two days, but the message they tried to get across was particular insofar as they would like to be considered not as stakeholders like the others, but rather as partners. That claim reflected the status of indigenous peoples in CBD who have managed since the mid-1990s to be acknowledged as fully fledged actors in negotiations. Their stakeholder status in IPBES was seen as a step backwards and a way of minimizing their ability to produce knowledge considered legitimate. During the IPBES-3 stakeholder days in Bonn, these representatives, who were less present than at IPBES-2, maintained the same position and systematically highlighted their specificity compared to other stakeholders. The two other groups (connected and peripheral) displayed uniform relational structures but heterogeneous contours of involvement.

The connected group contained individuals who frequently expressed views during the stakeholder days. Around 10 researchers, and notably German-speaking researchers and also some French-speakers linked to national or regional platforms for IPBES, regularly voiced views over the two days of the meeting. This group of researchers, which was particularly dynamic, knew the organizers very well and seemed familiar with the challenges of IPBES. Within this group, using the two variables previously identified (frequency of voicing views, and their content), two different contours of involvement were found. The first characterizes members who have assimilated the rules of the game and the objectives of the organizers and the second describes actors who frequently express themselves but in a more critical manner.

Last, the members of the peripheral group had a uniform relational structure and displayed, at first glance, the same contour of involvement because they seemed to be on stand-by. Compared to the connected group, they spoke out much less frequently, i.e., they paid attention to the debates but did not take part. They sometimes spoke out but were not a force for proposals. For example, the representative from the private sector, except when she participated in a round table, remained in the background of the debates about building the group of stakeholders. Likewise, as indicated above, the representatives of the private sector, like some other scientific experts for example, had other channels for expressing their position within IPBES and therefore confined themselves to stand-by mode in the stakeholder days. Others were learning their new role as stakeholders. For instance, some young recruits to IPBES were still discovering how the group worked and did not yet take the floor. Some of these stakeholders were in a position to take part in a cooperative manner in the deliberations of the group of stakeholders, while others, fewer in number, such as the 
representatives of indigenous peoples, were more critical of IPBES functioning. They might eventually no longer take part in it. This contour may also explain the disaffection of some individuals who may have taken part in the previous stakeholder days but, in view of the debates, had preferred to no longer attend.

\section{CONCLUSION}

The stakeholder concept encompasses a diversity of actors generally characterized by their institutional nature: NGO, research organizations, indigenous groups, private sector. This institutional diversity does not inform us about the dynamics of stakeholder participation in the IPBES process. In order to grasp those dynamics, we analyzed two particular dimensions: the relational structure of the group of stakeholders and their contours of involvement and showed that these two dimensions can combine in different ways, so that hypotheses can be put forward regarding the logics of future stakeholder participation in IPBES.

We showed that the way the group of stakeholders functions imposes a way of participating and a precise discursive style, which the participants are encouraged to follow. It is therefore within this framework proposed by the organizers of the stakeholder days that the stakeholders can express themselves. Indeed, the rather supervisory leadership of the group of stakeholders may lead to different logics. This leadership seems to be designed to utilitarian ends: favoring expressed viewpoints that converge with the organizers' expectations, or seeking to exclude or minimize expressed positions that would not seem to comply with them. The idea of a group of stakeholders, promoted by IPBES, is accompanied by a leadership/participation model that tends to enrol the stakeholders involved but may conversely marginalize some dissenting voices.

The IPBES case shows that "stakeholder democracy" (Bäckstrand 2006) is difficult to fully realize. Different categories of NSAs are present in stakeholder days. However, not all of them are fully involved in the process. This makes evident the inherent limits of "stakeholder democracy" in science-policy platforms. While international scientific organizations are fully participating even in the shaping of the science-policy platforms, the institutional process of involving NGOs, ILCs, and the private sector will always face the plurality of objectives and backgrounds of these organizations, not to mention geographic imbalances that do not favor African and Latin Americans NSAs.

We suggest some specific and concrete recommendations to improve the involvement of stakeholders in IPBES. First of all, we consider that it is important to build all IPBES actions on a participation philosophy that emphasizes empowerment, equity, trust, and learning as well as having a deliberative approach instead of a consensus one (Reed 2008). There is a need to strengthen the involvement of stakeholders from the scoping of the work program and in the task forces of IPBES. In addition, IPBES should transparently fund the participation of some stakeholders from developing countries. Both objectives are more likely to be achieved during regional assessments with a strategy of strengthening regional platforms as an intermediate level of science-policy interface between local/domestic and global issues dealing with biodiversity and ecosystem services. Some specific measures should be adopted to strengthen the involvement of ILCs such as taking into account ILCs' form of organizations into caucuses and adopting the spirit and principles of the multiple evidence base (MEB) approach for diverse knowledge and beliefs (Tengö et al. 2014). We also think that regular network analysis can help assess the institutional efforts of involving actors (Corbera et al. 2016, Morin et al. 2016). This may help determine where much effort should be focused or change the traditional methods of involving actors.

Responses to this article can be read online at: http://www.ecologyandsociety.org/issues/responses. $\mathrm{php} / 8961$

\section{Acknowledgments:}

Our research was funded by the Agence Nationale pour la Recherche française in the framework of the research project CIRCULEX "ANR-12-GLOB-0001-03 CIRCULEX"

\section{LITERATURE CITED}

Arts, B. 2000. Regimes, non-state actors and the state system: a 'structurational' regime model. European Journal of International Relations 6:513-542. http://dx.doi.org/10.1177/1354066100006004003

Bäckstrand, K. 2006. Democratizing global environmental governance? Stakeholder democracy after the World Summit on Sustainable Development. European Journal of International Relations 12:467-498. http://dx.doi.org/10.1177/1354066106069321

Berger, P. L., and T. Luckmann. 1991. The social construction of reality: a treatise in the sociology of knowledge. Penguin, London, UK.

Betsill, M., and E. Corell. 2008. NGO diplomacy. The influence of nongovernmental organizations in international environmental negotiations. MIT Press, Cambridge, Massachusetts, USA.

Buizer, M., B. Arts, and K. Kok. 2011. Governance, scale, and the environment: the importance of recognizing knowledge claims in transdisciplinary arenas. Ecology and Society 16(1):21. http://dx.doi.org/10.5751/es-03908-160121

Cefaï, D., M. Carrel, J. Talpin, N. Eliasoph, and P. Lichterman. 2012. Ethnographies de la participation. Participations 7-48. http://dx.doi.org/10.3917/parti.004.0005

Clapp, J. 2005. Transnational corporations and global environmental governance. Pages 284-297 in P. Dauvergne, editor. Handbook of global environmental politics. Edward Elgar, Cheltenham, UK. http://dx.doi.org/10.4337/9781845425555.00028

Coombe, R. J. 2001. Recognition of indigenous peoples' and community traditional knowledge in international law. St Thomas Law Review 14:275-285.

Corbera, E., L. Calvet-Mir, H. Hughes, and M. Paterson. 2016. Patterns of authorship in the IPCC Working Group III report. Nature Climate Change 6(1):94-99. http://dx.doi.org/10.1038/ nclimate 2782

Duperray, F., M. Hrabanski, and M. Oubenal. 2016. First thematic assessment on pollination: between the legitimation of IPBES and tensions regarding the selection of knowledge and 
experts. Pages 211-227 in M. Hrabanski and D. Pesche, editors. The intergovernmental platform on biodiversity and ecosystem services (IPBES): meeting the challenge of biodiversity conservation and governance. Routledge, London, UK.

Goffman, E. 2013. Comment se conduire dans les lieux publics: notes sur l'organisation sociale des rassemblements. Économica, Paris, France.

Higgott, R. A., G. R. D. Underhill, and A. Bieler. 2000. Non-state actors and authority in the global system. Routledge, London, UK.

Hogl, K., E. Kvarda, R. Nordbeck, and M. Pregernig. 2012. Environmental governance. The challenge of legitimacy and effectiveness. Edward Elgar, Cheltenham, UK. http://dx.doi. org/10.4337/9781849806077

IPBES. 2013. Draft stakeholder engagement strategy for supporting the implementation of the Platform's work programme. UNEP - IPBES/2/13, 9. IPBES, Bonn, Germany.

IPBES. 2014. Revised draft stakeholder engagement strategy deliverable $4(d)$. United Nations - IPBES/3/16, 8. IPBES, Bonn, Germany.

Isaac, M. E., B. H. Erickson, S. Quashie-Sam, and V. R. Timmer. 2007. Transfer of knowledge on agroforestry management practices: the structure of farmer advice networks. Ecology and Society 12(2):32. http://dx.doi.org/10.5751/es-02196-120232

Kowalski, A. A., and L. D. Jenkins. 2015. The role of bridging organizations in environmental management: examining social networks in working groups. Ecology and Society 20(2):16. http:// dx.doi.org/10.5751/es-07541-200216

Lazega, E. 2001. The collegial phenomenon: the socialmechanisms of cooperation among peers in a corporate law partnership. Oxford University Press, Oxford, UK. http://dx.doi.org/10.1093/acprof: oso/9780199242726.001.0001

Lazega, E. 2007.Réseaux sociaux et structures relationnelles. PUF, Paris, France.

Lazega, E., L. Mounier, T, Snijders, and P. Tubaro. 2012. Norms, status and the dynamics of advice networks: a case study. Social Networks 34:323-332. http://dx.doi.org/10.1016/j.socnet.2009.12.001

Lazega, E., and P. E. Pattison. 1999. Multiplexity, generalized exchange and cooperation in organizations: a case study. Social Networks 21:67-90. http://dx.doi.org/10.1016/S0378-8733(99) $\underline{00002-7}$

Lorrain, F., and H. C. White. 1971. Structural equivalence of individuals in social networks. Journal of Mathematical Sociology 1:49-80. http://dx.doi.org/10.1080/0022250X.1971.9989788

Mauro, F., and P. D. Hardison. 2000. Traditional knowledge of indigenous and local communities: international debate and policy initiatives. Ecological Applications 10:1263-1269. http://dx. doi.org/10.1890/1051-0761(2000)010[1263:TKOIAL]2.0.CO;2

Mitchell, R. B. 2010.International politics and the environment. Sage, Thousand Oaks, California, USA.
Morin J. F., S. Louafi, A. Orsini, and M. Oubenal. 2016. Boundary organizations in regime complexes: a social network profile of IPBES. Journal of International Relations and Development 1-35. http://dx.doi.org/10.1057/s41268-016-0006-8

Nasiritousi, N., M. Hjerpe, and B.-O. Linnér. 2016. The roles of non-state actors in climate change governance: understanding agency through governance profiles. International Environmental Agreements: Politics, Law and Economics 16:109. http://dx.doi. org/10.1007/s10784-014-9243-8

Opgenoorth, L., and D. P. Faith. 2013. The intergovernmental science-policy platform on biodiversity and ecosystem services (IPBES), up and walking. Frontiers of Biogeography 5.

Reed, M. S. 2008. Stakeholder participation for environmental management: a literature review. Biological Conservation 141 (10):2417-2431 http://dx.doi.org/10.1016/j.biocon.2008.07.014

Schroeder, H. 2010. Agency in international climate negotiations: the case of indigenous peoples and avoided deforestation. International Environmental Agreements: Politics, Law and Economics 10:317-332. http://dx.doi.org/10.1007/s10784-010-9138-2

Scott, J. 2014. The SAGE handbook of social network analysis: a handbook. SAGE, Thousand Oaks, California, USA. http://dx. doi.org/10.4135/9781446294413

Tengö, M., E. S. Brondizio, T. Elmqvist, P. Malmer, and M. Spierenburg. 2014. Connecting diverse knowledge systems for enhanced ecosystem governance: the multiple evidence base approach. Ambio 43(5):579-591. http://dx.doi.org/10.1007/ s13280-014-0501-3

Thaman, R., P. Lyver, R. Mpande, E. Perez, J. Cariño, and K. Takeuchi. 2013. The contribution of indigenous and local knowledge systems to IPBES: building synergies with science. IPBES Expert Meeting Report. UNESCO/UNU, Paris, France.

Turnhout, E., B. Bloomfield, M. Hulme, J. Vogel, and B. Wynne. 2012. Conservation policy: listen to the voices of experience. Nature 488:454-455. http://dx.doi.org/10.1038/488454a

Van Vree, W. 2001. Meetings, manners, and civilization: the development of modern meeting behaviour. Leicester University Press, London, UK.

Wallbott, L. 2014. Indigenous peoples in UN REDD+ negotiations: "importing power" and lobbying for rights through discursive interplay management. Ecology and Society 19(1):21. http://dx.doi.org/10.5751/ES-06111-190121

Wasserman, S., and K. Faust. 1994. Social network analysis: methods and applications. Cambridge University Press, Cambridge, UK. http://dx.doi.org/10.1017/cbo9780511815478 
Appendix 1. The methodological aspects of the approach adopted for calculating the relational proximity of stakeholders, and the dendrogram.

Based on the matrix of the advice network between stakeholders, we calculated the relational proximity between two individuals in the network using hierarchical clustering (Ward's method). Using Pajek software, which applies the Ward clustering method, we were able to classify individuals according to their similarity and/or difference of relationships and visualize their relational proximity and/or distance on a dendrogram of similarities (see figure below). The dendrogram is read from left to right considering that the stakeholders with the closest relational profile are those for which the two lines join first (De Nooy et al. 2004:267). The length of the horizontal lines, between their point of departure and the place where they cross over, is the difference in relational profile between stakeholders or groups. A vertical line has been traced that distinguishes between four groups according to relational proximity. The interpretations then made of the composition of the groups takes into account the organizational attributes of the stakeholders. 
Fig. A1.1. Dendrogram including the four groups of stakeholders.

\section{Pajek - Ward $[0.00,2.29]$}

Names have been

remaved ta preserve the ananymity of

adars.

of

Peripheral

Connected

Organizers

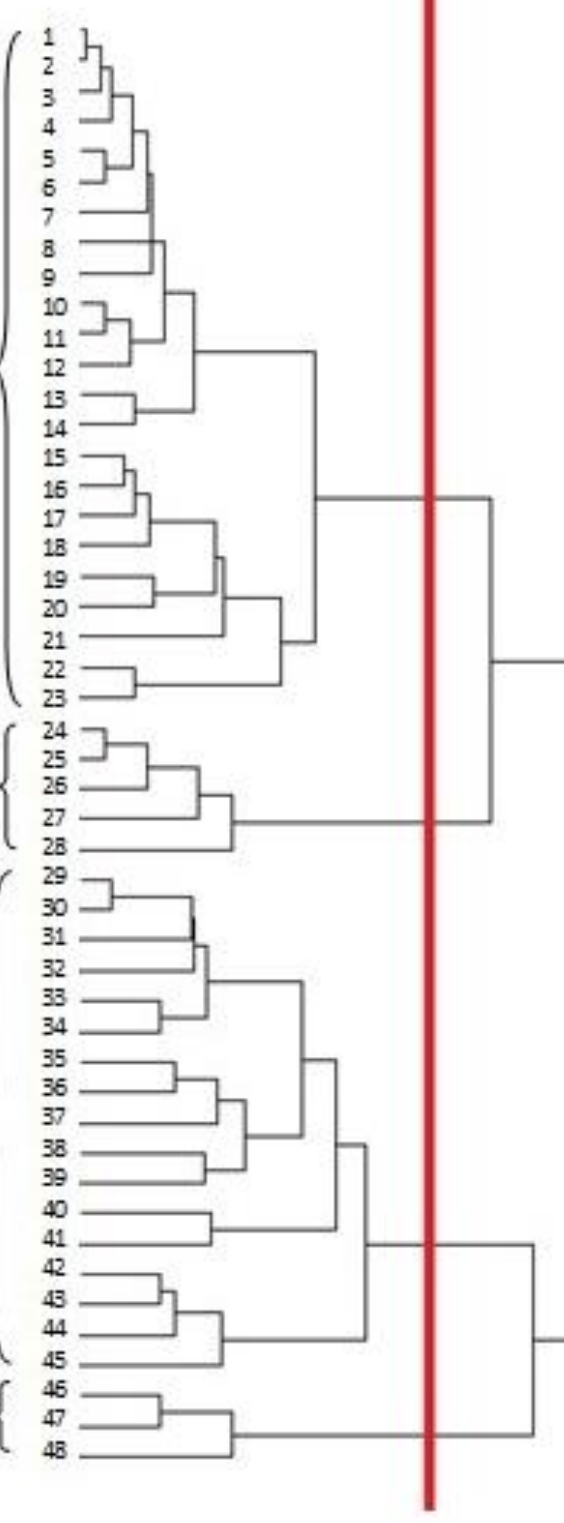

